\title{
Synthesis of ZnW04/Cu20 Composites and Efficient Catalytic Properties for 4-nitrophenol Removal
}

\section{Ziwei Wang}

China West Normal University

Fengping Fu

China West Normal University

Qian He

China West Normal University

Ting Zhu

China West Normal University

Fang Liao ( $\square$ liaofang407@163.com )

China West Normal University https://orcid.org/0000-0002-3024-9339

\section{Research Article}

Keywords: 4-nitrophenol, Cu20 matrix composites, ZnWO4, Catalytic reduction

Posted Date: October 22nd, 2021

DOI: https://doi.org/10.21203/rs.3.rs-1000941/v1

License: (우 This work is licensed under a Creative Commons Attribution 4.0 International License. Read Full License 


\section{Abstract}

Preparation of $\mathrm{ZnWO}_{4} / \mathrm{Cu}_{2} \mathrm{O}$ composite materials by environmental protection experimental method. $\mathrm{ZnWO}_{4}$ nanorods were prepared by a simple hydrothermal method, and then $\mathrm{ZnWO}_{4} / \mathrm{Cu}_{2} \mathrm{O}$ composites were prepared by chemical precipitation method. The experimental method is simple and clean. Due to the unique structural characteristics of $\mathrm{Cu}_{2} \mathrm{O}$, the wide band gap of $\mathrm{ZnWO}_{4}$ was improved and the $\mathrm{ZnWO}_{4} / \mathrm{Cu}_{2} \mathrm{O}$ composite with better catalytic performance was generated. Various tests show that the catalytic performance and stability of $\mathrm{ZnWO}_{4} / \mathrm{Cu}_{2} \mathrm{O}$ is not lower than that of $\mathrm{ZnWO}_{4}$. Among them, $\mathrm{ZnWO}_{4} / \mathrm{Cu}_{2} \mathrm{O}-5$ has the best catalytic degradation effect. The $\mathrm{Cu}-\mathrm{H}$ generated during the degradation of 4-nitrophenol (4NP) prevents the oxidation of $\mathrm{Cu}^{+}$, and the neutral product 4-aminophenol (4-AP) is easier to fall off, which improves its recycling efficiency. These encouraging results show that the $\mathrm{ZnWO}_{4} / \mathrm{Cu}_{2} \mathrm{O}$ composites have great potential to degrade 4-NP.

\section{Introduction}

- 4-nitrophenol (4-NP) has high toxicity and long half-life in the natural environment, which causes serious pollution to the water environment. It is easy to accumulate in humans and animals to cause cancer or physical deformity [1, 2]. 4-aminophenol (4-AP) as the intermediate of 4-NP catalytic degradation is widely used in medicine, dyes, pesticides and other fields. Among many methods for reducing 4-NP to 4-AP, catalytic hydrogenation reduction method is the best, which has the advantages of high conversion efficiency and mild operating conditions [3]. Among them, noble metal nanoparticles have the best catalytic effect $[4,5]$. But it is expensive, limited reserves and difficult to large-scale promotion. Scientists are more focused on the development of cheap, abundant non-precious metal catalysts.

- $\mathrm{Cu}_{2} \mathrm{O}$ is a typical P-type direct band gap semiconductor material that can be excited by visible light. Its band gap is about $2.17 \mathrm{eV}$, and has good photoelectric properties [6, 7]. $\mathrm{Cu}_{2} \mathrm{O}$ nanoparticles, not only has high photocatalytic activity, bactericidal activity, photoelectron conversion activity, but also has the advantages of high surface energy and large specific surface area [8]. This makes $\mathrm{Cu}_{2} \mathrm{O}$ have applications in photocatalysis [9], photohydrolysis of hydrogen in aquatic products [10], CO oxidation [11], $\mathrm{CO}_{2}$ reduction [12], and gas sensing [13]. However, the band gap of $\mathrm{Cu}_{2} \mathrm{O}$ is narrow. And its reaction rate is slow, easy to be oxidized, low cycle utilization. In order to eliminate these shortcomings, researchers have made many efforts.

- Since scientists found $\mathrm{ZnWO}_{4}$, people have had a strong interest in it. $\mathrm{ZnWO}_{4}$ is a wide band gap semiconductor photocatalyst. $\mathrm{Zn}^{2+}$ and $\mathrm{W}^{6+}$ have electronic configurations of $\mathrm{d} 10$ and $\mathrm{d} 0$, and are located at the centers of $\mathrm{ZnO}_{6}$ and $\mathrm{WO}_{6}$. Therefore, they have high electron mobility, which have a matching valence band relationship with $\mathrm{Cu}_{2} \mathrm{O}$ [14]. In this experiment, $\mathrm{ZnWO}_{4} / \mathrm{Cu}_{2} \mathrm{O}$ composites are prepared according to the band gap characteristics of the two. Explore whether the photocatalytic properties of composite materials have improved.

- Therefore, in this study, $\mathrm{ZnWO}_{4}$ nanorods with stable structure were prepared by simple hydrothermal method, and $\mathrm{ZnWO}_{4} / \mathrm{Cu}_{2} \mathrm{O}$ was prepared by chemical precipitation method. Encouraging experimental 
results have been obtained, among which $\mathrm{ZnWO}_{4} / \mathrm{Cu}_{2} \mathrm{O}-5$ has the best catalytic degradation effect. The modified catalyst improved the separation ability of electron-hole and enhanced the photocatalytic activity. The oxidation of $\mathrm{Cu}^{+}$was prevented by $\mathrm{Cu}-\mathrm{H}$ generated in the catalytic degradation process. The neutral degradation product 4-AP made it easier to fall off and improved its recycling efficiency. The efficient recycling of $\mathrm{ZnWO}_{4} / \mathrm{Cu}_{2} \mathrm{O}-\mathrm{X}$ is in line with the concept of environmental protection, which is a more economical and feasible process. and the $\mathrm{ZnWO}_{4} / \mathrm{Cu}_{2} \mathrm{O}$ catalyst is characterized by XRD, SEM, UV-Vis, TEM, XPS and HRTEM to determine the nature of catalytic activity of catalyst.

\section{Experimental}

\subsection{Materials}

Zinc nitrate hexahydrate and copper acetate monohydrate were purchased from Chengdu Kelong reagent plant. Sodium tungstate dihydrate was purchased from Tianjin Ruijinte Chemical Co., Ltd.. Sodium hydroxide and barium sulfate were purchased from Shandong Xiya Chemical Industry Co., Ltd.. Anhydrous glucose was purchased from Aladdin Reagent (Shanghai ) Co., Ltd., and anhydrous ethanol was purchased from Tianjin Fuchen Chemical Reagent Plant. All chemical reagents were analytically pure.

\section{$2.2 \mathrm{ZnWO}_{4} / \mathrm{Cu}_{2} \mathrm{O}$ composites preparation}

\subsection{1 $\mathrm{ZnWO}_{4}$ nanorods preparation}

$\mathrm{ZnWO}_{4}$ nanorods were prepared by hydrothermal method. $15 \mathrm{ml} 6.7 \mathrm{M} \mathrm{Na}_{2} \mathrm{WO}_{4} \cdot 2 \mathrm{H}_{2} \mathrm{O}$ solution was dropped into $15 \mathrm{ml} 6.7 \mathrm{M} \mathrm{Zn}\left(\mathrm{NO}_{3}\right) \cdot 6 \mathrm{H}_{2} \mathrm{O}$ solution. The $\mathrm{pH}$ was adjusted to 9 with an intelligent $\mathrm{pH}$ meter, stirred for $30 \mathrm{~min}$, and transferred to a stainless steel autoclave. The temperature was adjusted to $453 \mathrm{~K}$ for $12 \mathrm{~h}$. After the reaction, the precipitate was collected and washed several times with deionized water and anhydrous ethanol. Then the sample was dried by vacuum drying box, and the powder was grinded by bowl after drying.

\subsection{2 $\mathrm{ZnWO}_{4} / \mathrm{Cu}_{2} \mathrm{O}-\mathrm{X}$ composites preparation}

$\mathrm{ZnWO}_{4}(0.0039 \mathrm{~g} \otimes 0.0117 \mathrm{~g} \otimes 0.0195 \mathrm{~g} \otimes 0.0273 \mathrm{~g})$ were added into $\left(\mathrm{CH}_{3} \mathrm{OO}\right)_{2} \mathrm{Cu} \cdot \mathrm{H}_{2} \mathrm{O}$ aqueous solution of 25 $\mathrm{ml} 0.05 \mathrm{M}(\mathrm{X}=1 \otimes 3 \otimes 5 \bigotimes 7)$ for $30 \mathrm{~min}$. Then stir at $313 \mathrm{~K}$ for $10 \mathrm{~min}$, slowly drop $4 \mathrm{ml} 1 \mathrm{M} \mathrm{NaOH}$, stir at constant temperature for $10 \mathrm{~min}$, add $15 \mathrm{ml} 1 \mathrm{M}$ glucose, stir at constant temperature for $2 \mathrm{~h}$. The samples were obtained, and washed with deionized water and anhydrous ethanol several times, dried in vacuum dryer. The process is demonstrated in Fig. 1 .

Fig. 1Preparation process of $\mathrm{ZnWO}_{4} / \mathrm{Cu}_{2} \mathrm{O}$ composite

\section{3 $\mathrm{ZnWO}_{4} / \mathrm{Cu}_{2} \mathrm{O}-\mathrm{X}$ composites characterization}

Tecnai G2F30 transmission electron microscope (TEM) and high-resolution transmission electron microscope (HRTEM) were used for transmission. UV-Vis diffuse reflectance spectra were measured by UV- 
3600 spectrophotometer. The scanning range was from $200 \mathrm{~nm}$ to $800 \mathrm{~nm}$. The crystal phase of the sample was characterized by BRUCKER D8ADVANCE X-ray powder diffractometer in the range of $10-80^{\circ}$. X-ray diffraction (XRD) was performed with a 250Xi diffractometer. The energy spectrum was analyzed by SU8020 field emission scanning electron microscope (SEM).

\subsection{Evaluation of catalysts performance}

\subsubsection{Catalytic activity for hydrogenation of catalyst test}

$10 \mathrm{mg}$ catalyst was dissolved in $10 \mathrm{ml}$ deionized water, and ultrasonic dispersion was uniform. $10 \mathrm{ml} 0.24$ $\mathrm{M} \mathrm{NaBH}_{4}$ aqueous solution was added to $90 \mathrm{ml} 2.2 \times 10^{-4} \mathrm{~mol} / \mathrm{L}$ 4-NP. $0.02 \mathrm{ml}$ catalyst solution was accurately removed by liquid gun and added to the above mixed solution. Add the catalyst and start timing. Remove $3.5 \mathrm{ml}$ of solution every other time in the colorimetric dish. The ultraviolet spectrophotometer was immediately used to monitor the change of 4-NP ion absorption peak at $400 \mathrm{~nm}$ of purple wavelength in the scanning range of $250 \mathrm{~nm}-500 \mathrm{~nm}$. The reaction rate constant is calculated by absorbance. The whole process was continuously stirred in a constant temperature water bath at $25^{\circ} \mathrm{C}$.

\subsubsection{Hydrogenation catalyst stability test}

$5 \mathrm{ml}$ of 4-NP and $5 \mathrm{ml}$ of $\mathrm{NaBH}_{4}$ were mixed and diluted to $100 \mathrm{ml}$, and $0.2 \mathrm{ml}$ of $1 \mathrm{mg} / \mathrm{ml}$ catalyst was added. The intensity of the absorption peak of the solution was detected by UV spectrophotometer at a certain interval. The stability of the solution was tested by repeated dripping. $1 \mathrm{ml}$ of $1 \times 10^{-2} \mathrm{~mol} / \mathrm{L} 4-\mathrm{NP}$ was added at each reaction and repeated 15 times.

\section{Results And Discussion}

\subsection{Morphology and microstructure analysis}

Fig. $2 \mathrm{SEM}$ images of (a-b) $\mathrm{ZnWO}_{4} ;(\mathbf{c}-\mathbf{d}) \mathrm{Cu}_{2} \mathrm{O}$; (e-f) $\mathrm{ZnWO}_{4} / \mathrm{Cu}_{2} \mathrm{O}$

$\mathrm{ZnWO}_{4}$ SEM images prepared by hydrothermal method are shown in Fig. $2 \mathbf{a}$ and $\mathbf{b}$. The results show that the size of $\mathrm{ZnWO}_{4}$ nanorods is uniform and the diameter is about $50 \mathrm{~nm}$. Fig. $2 \mathrm{c}$ and $\mathbf{d}$ show that the $\mathrm{Cu}_{2} \mathrm{O}$ spheres synthesized by chemical precipitation method are about $500 \mathrm{~nm}$ to $900 \mathrm{~nm}$, and the surface is rough and not smooth, which greatly improves its activity. $\mathrm{ZnWO}_{4} / \mathrm{Cu}_{2} \mathrm{O}$ composites formed by chemical precipitation method are shown in Fig. $2 \mathbf{e}$ and $\mathbf{f}$. It can be seen that $\mathrm{ZnWO}_{4}$ is closely adhered to the surface of $\mathrm{Cu}_{2} \mathrm{O}$ and does not change its morphology. Close contact ensures the effective transfer of charge during catalytic hydrogenation reduction. The mapping of $\mathrm{ZnWO}_{4} / \mathrm{Cu}_{2} \mathrm{O}$ is shown in Fig. 3, which shows that $\mathrm{Zn}, \mathrm{O}$, $\mathrm{Cu}$ and $\mathrm{W}$ exist in $\mathrm{ZnWO}_{4} / \mathrm{Cu}_{2} \mathrm{O}$, and are uniformly distributed in the sample.

The TEM and HRTEM images of $\mathrm{ZnWO}_{4} / \mathrm{Cu}_{2} \mathrm{O}$ composites are shown in Fig. 4. According to Fig. 4, the lattice spacing of $\mathrm{Cu}_{2} \mathrm{O}$ is $0.24 \mathrm{~nm}$, which corresponds to 111 planes. The lattice spacing of $0.37 \mathrm{~nm}$ corresponds to 011 plane of $\mathrm{ZnWO}_{4}$. At the same time, as shown in Fig. 4c, clear stripe spacing proves that $\mathrm{Cu}_{2} \mathrm{O}$ and $\mathrm{ZnWO}_{4}$ have good crystallinity, and they have matching crystal plane spacing and lattice plane. 
Fig. 4TEM and HRTEM images of $\mathrm{ZnWO}_{4} / \mathrm{Cu}_{2} \mathrm{O}$

\subsection{Material composition and valence analysis (XRD and XPS)}

As shown in Fig. 5, the black curve is $\mathrm{ZnWO}_{4}$ nanowires. Its characteristic diffraction peaks are about $23.8^{\circ}$, $24.6^{\circ}, 30.7^{\circ}, 36.3^{\circ}, 41.2^{\circ}, 53.6^{\circ}$. Which are matched with (110), (200), (210), (211), (220), (310), (222), (320), (321), (400) and (421) crystal planes of $\mathrm{ZnWO}_{4}$ (JCPDS NO.15-0774) [15]. The red curve is $\mathrm{Cu}_{2} \mathrm{O}$. Its characteristic diffraction peaks are $29.6^{\circ}, 36.5^{\circ}, 42.4^{\circ}, 61.6^{\circ}, 73.7^{\circ}$, corresponding to the (110), (111), (200), (220), (311) crystal planes of $\mathrm{Cu}_{2} \mathrm{O}$ crystal. Which are consistent with the (JCPDS N0.77-0119) [29] card. When $\mathrm{ZnWO}_{4} / \mathrm{Cu}_{2} \mathrm{O}-\mathrm{X}$ composite is synthesized, with the increase of $\mathrm{ZnWO}_{4}$, the XRD pattern of $\mathrm{ZnWO}_{4} / \mathrm{Cu}_{2} \mathrm{O}-\mathrm{X}$ composite does not appear the characteristic peak of $\mathrm{ZnWO}_{4}$. There is only the narrow and sharp peak of $\mathrm{Cu}_{2} \mathrm{O}$, but the peak position is shifted. No other changes were detected, indicating the high purity of the complex. The main reason for the absence of $\mathrm{ZnWO}_{4}$ characteristic peaks may be the content and particle size. The content of $\mathrm{Zn}$ and $\mathrm{Cu}$ in the synthesized compound were determined by inductively coupled plasma atomic emission spectrometer (ICP-OES), and the results are shown in Table. 1. The low content and high dispersion of $\mathrm{ZnWO}_{4}$ can not cause the morphological change of $\mathrm{Cu}_{2} \mathrm{O}$, which is consistent with the results of SEM and TEM.

Table 1

The ratio of the amount of $\mathrm{Zn} / \mathrm{Cu}$ in the $\mathrm{ZnWO}_{4} / \mathrm{Cu}_{2} \mathrm{O}$ compositee

\begin{tabular}{|lll|}
\hline catalyst & theoretical value & actual value \\
\hline $\mathrm{ZnWO}_{4} / \mathrm{Cu}_{2} \mathrm{O}-1$ & $1 \%$ & $1.3 \%$ \\
\hline $\mathrm{ZnWO}_{4} / \mathrm{Cu}_{2} \mathrm{O}-3$ & $3 \%$ & $4.0 \%$ \\
\hline $\mathrm{ZnWO}_{4} / \mathrm{Cu}_{2} \mathrm{O}-5$ & $5 \%$ & $6.8 \%$ \\
\hline $\mathrm{ZnWO}_{4} / \mathrm{Cu}_{2} \mathrm{O}-7$ & $7 \%$ & $9.4 \%$ \\
\hline
\end{tabular}

Fig. 5 XRD patterns of $\mathrm{ZnWO}_{4} ; \mathrm{Cu}_{2} \mathrm{O} ; \mathrm{ZnWO}_{4} / \mathrm{Cu}_{2} \mathrm{O}-\mathrm{X}$

The characteristic peaks of Zn, W, O, Cu can be observed are shown in Fig. 6. Fig. 6b shows the spectra of Zn 2p, showing two peaks of $1021.9 \mathrm{eV}$ and $1044.7 \mathrm{eV}$, corresponding to Zn $2 \mathrm{p}_{3 / 2}$ and Zn $2 \mathrm{p}_{1 / 2}$, respectively. Fig. $6 \mathrm{c}$ is the XPS spectrum of W4f, showing two peaks of $35.8 \mathrm{eV}$ and $37.9 \mathrm{eV}$, corresponding to $\mathrm{W}_{4} \mathrm{f}_{7 / 2}$ and $4 \mathrm{f}_{5 / 2}$, which determines the existence of $\mathrm{W} 4 \mathrm{f}$. Fig. $6 \mathrm{~d}$ is 0 , showing three peaks at $530.3 \mathrm{eV}$, $531.1 \mathrm{eV}$ and $532.2 \mathrm{eV}$. The peak at $530.3 \mathrm{eV}$ corresponds to the lattice oxygen in $\mathrm{Cu}_{2} \mathrm{O}$, and the peak at $531.1 \mathrm{eV}$ corresponds to the lattice oxygen in $\mathrm{ZnWO}_{4}$. The spectral result of $\mathrm{Cu} 2 \mathrm{p}$ is shown in Fig. 6e. There are two peaks at $932.9 \mathrm{eV}$ and $952.3 \mathrm{eV}$, corresponding to $\mathrm{Cu} 2 \mathrm{p}_{3 / 2}$ and $\mathrm{Cu} 2 \mathrm{p}_{1 / 2}$. XRD and XPS analysis showed that $\mathrm{Cu}_{2} \mathrm{O}$ and $\mathrm{ZnWO}_{4}$ coexist in $\mathrm{Cu}_{2} \mathrm{O} / \mathrm{ZnWO}_{4}$. 
Fig. 6 a XPS survey spectra; High-resolution XPS spectra of b Zn 2p; c W 4f; d 0 1s and e Cu 2p

\section{3 $\mathrm{N}_{2}$ adsorption-desorption characterization of catalysts}

The $\mathrm{N}_{2}$ adsorption-desorption isotherms of $\mathrm{Cu}_{2} \mathrm{O}$ and $\mathrm{ZnWO}_{4} / \mathrm{Cu}_{2} \mathrm{O}$ and their corresponding pore size distribution curves are shown in Fig. 7. It can be seen that $\mathrm{Cu}_{2} \mathrm{O}$ and $\mathrm{ZnWO}_{4} / \mathrm{Cu}_{2} \mathrm{O}$ are typical type IV isotherms, indicating that $\mathrm{Cu}_{2} \mathrm{O}$ and $\mathrm{ZnWO}_{4} / \mathrm{Cu}_{2} \mathrm{O}$ are mesoporous materials. In $0 \sim 0.9 \mathrm{~V}$, the adsorption capacity of $\mathrm{ZnWO}_{4} / \mathrm{Cu}_{2} \mathrm{O}$ is low. While in the $0.9 \sim 1.0 \mathrm{~V}$, the absorption capacity is greatly improved. On the whole, the absorption capacity of $\mathrm{ZnWO}_{4} / \mathrm{Cu}_{2} \mathrm{O}$ is low, indicating that the specific surface area is not large. But $\mathrm{ZnWO}_{4} / \mathrm{Cu}_{2} \mathrm{O}$ has stronger absorption capacity than $\mathrm{Cu}_{2} \mathrm{O}$, indicating that its specific surface area is larger than $\mathrm{Cu}_{2} \mathrm{O}$. Which is consistent with the test results. The BET algorithm shows that the specific surface area of $\mathrm{Cu}_{2} \mathrm{O}$ is $1.9 \mathrm{~m}^{2} / \mathrm{g}$, and that of $\mathrm{ZnWO}_{4} / \mathrm{Cu}_{2} \mathrm{O}$ is $2.7 \mathrm{~m}^{2} / \mathrm{g}$. The average pore sizes are $4.2 \mathrm{~nm}$ and $6.4 \mathrm{~nm}$, and the pore volumes are $1.3 \times 10^{-3} \mathrm{~cm}^{3} / \mathrm{g}$ and $2.8 \times 10^{-3} \mathrm{~cm}^{3} / \mathrm{g}$, respectively. It indicates that the combination of the two is conducive to improving the specific surface area, pore size and pore volume, but the space for improvement is very small.

Fig. $7 \mathrm{~N}_{2}$ adsorption and desorption curves ofa $\mathrm{Cu}_{2} \mathrm{O} ; \mathbf{b} \mathrm{ZnWO}_{4} / \mathrm{Cu}_{2} \mathrm{O}$

\subsection{Activity detection of catalysts}

The activity of the catalyst was determined by the degradation degree of 4-NP by the catalyst. The standard schematic diagram of catalytic reduction of 4-NP are shown in Fig. 8a. Under neutral and acidic conditions, the peaks of 4-NP at about $317 \mathrm{~nm}$. When $\mathrm{NaBH}_{4}$ is added, the solution is alkaline. 4-NP is dissociated into ions, and the maximum absorption peak shifts to $400 \mathrm{~nm}$. When the catalyst is added, 4-AP is rapidly generated. And its characteristic absorption peak is at $300 \mathrm{~nm}$. There is no by-product in the whole reaction process [16]. The absorbance spectra of $\mathrm{ZnWO}_{4}, \mathrm{Cu}_{2} \mathrm{O}, \mathrm{ZnWO}_{4} / \mathrm{Cu}_{2} \mathrm{O}-1, \mathrm{ZnWO}{ }_{4} / \mathrm{Cu}_{2} \mathrm{O}-3, \mathrm{ZnWO}_{4} / \mathrm{Cu}_{2} \mathrm{O}-5$, $\mathrm{ZnWO}_{4} / \mathrm{Cu}_{2} \mathrm{O}-7$ changes with time are shown in Fig. 8(b-g). It can be seen from Fig. $8 \mathrm{~b}$ that when $\mathrm{ZnWO}_{4}$ is added, the absorbance almost don't change, which proved that $\mathrm{ZnWO}_{4}$ is no catalytic. When other catalysts are added, the absorbance changes obviously. The degradation efficiency of $\mathrm{ZnWO}_{4} / \mathrm{Cu}_{2} \mathrm{O}$ composite for 4$\mathrm{NP}$ is better than that of $\mathrm{Cu}_{2} \mathrm{O}$. The catalytic degradation efficiency from high to low are $\mathrm{ZnWO}_{4} / \mathrm{Cu}_{2} \mathrm{O}-5$, $\mathrm{ZnWO}_{4} / \mathrm{Cu}_{2} \mathrm{O}-3, \mathrm{ZnWO}_{4} / \mathrm{Cu}_{2} \mathrm{O}-7, \mathrm{ZnWO}_{4} / \mathrm{Cu}_{2} \mathrm{O}-1, \mathrm{Cu}_{2} \mathrm{O}$. Therefore, the combination of the two can modify $\mathrm{Cu}_{2} \mathrm{O}$ and improve the catalytic activity of $\mathrm{Cu}_{2} \mathrm{O}$.

In order to more intuitively observe the influence of $\mathrm{ZnWO}_{4} / \mathrm{Cu}_{2} \mathrm{O}-\mathrm{X}$ on the catalytic performance, we selected the absorbance at $400 \mathrm{~nm}$ to calculate the value of $\mathrm{C}_{t} / \mathrm{C}_{0}$ for comparison $\left(\mathrm{C}_{0}\right.$ and $\mathrm{C}_{\mathrm{t}}$ are the concentration of 4-NP solution at time 0 and time $t$ ). As the reaction proceeds, the ratio of $C_{t} / C_{0}$ to time $t$ becomes smaller and smaller. Which indicates that the content of 4-NP in the whole reaction system becomes lower and lower. The linear fitting of Fig. 8a show the linear relationship was good and conforms to the first-order kinetics. So $\left(A_{0}\right.$ and $A_{t}$ are the absorbance of 4-NP solution at 0 and $t, K_{a p p}$ is the apparent rate constant, $\mathrm{t}$ is the reaction time):

$\ln \left(A_{t} / A_{0}\right)=\ln \left(C_{t} / C_{0}\right)=-k_{a p p} t 1$ 
The relationship between $\mathrm{C}_{t} / \mathrm{C}_{0}$ and $\mathrm{t}$ is shown in Fig. 9a. It can be seen that the conversion rate of $\mathrm{ZnWO}_{4} / \mathrm{Cu}_{2} \mathrm{O}-5$ is the highest and that of $\mathrm{Cu}_{2} \mathrm{O}$ is the lowest at the same time. So the catalytic activity of $\mathrm{ZnWO}_{4} / \mathrm{Cu}_{2} \mathrm{O}-5$ is higher than that of $\mathrm{Cu}_{2} \mathrm{O}$.

The relationship between $\ln \left(\mathrm{C}_{\mathrm{t}} / \mathrm{C}_{0}\right)$ and $\mathrm{t}$ is shown in Fig. $9 \mathrm{~b}$. It can be seen that the reaction rate of $\mathrm{ZnWO}_{4} / \mathrm{Cu}_{2} \mathrm{O}-5$ is the fastest. Linear slopes were obtained by linear fitting. The kapp values of $\mathrm{Cu}_{2} \mathrm{O}$, $\mathrm{ZnWO}_{4} / \mathrm{Cu}_{2} \mathrm{O}-1, \mathrm{ZnWO}_{4} / \mathrm{Cu}_{2} \mathrm{O}-3, \mathrm{ZnWO}_{4} / \mathrm{Cu}_{2} \mathrm{O}-5$ and $\mathrm{ZnWO}_{4} / \mathrm{Cu}_{2} \mathrm{O}-7$ were $8.2 \times 10^{-3} \mathrm{~s}^{-1}, 15.91 \times 10^{-3} \mathrm{~s}^{-1}$, $25.2 \times 10^{-3} \mathrm{~s}^{-1}, 20.6 \times 10^{-3} \mathrm{~s}^{-1}$ and $6.2 \times 10^{-3} \mathrm{~s}^{-1}$, respectively. In order to show the advantages of composites more clearly, the activation factors of $\mathrm{ZnWO}_{4} / \mathrm{Cu}_{2} \mathrm{O}-5$ were calculated by formula 2 .

$\mathrm{k}^{\prime}=\mathrm{k}_{a p p} / \mathrm{m} 2$

Fig. 9 Different catalysts of $a C_{t} / C_{0}$ curve graph with time; $b$ netic fitting graph

The results showed that the activation factors of $\mathrm{Cu}_{2} \mathrm{O}$ and $\mathrm{ZnWO}_{4} / \mathrm{Cu}_{2} \mathrm{O}-5$ were $31 \times 10^{-3} \mathrm{~s}^{-1} \mathrm{mg}^{-1}$ and $126 \times 10^{-3} \mathrm{~s}^{-1} \mathrm{mg}^{-1}$, respectively, indicating that its catalytic performance was better than that of most catalysts. As shown in Table. 2. 
Table 2

Comparison of the rate constant $(k)$ and activity factor $\left(k^{\prime}\right)$ of different catalysts used to reduce 4-NP to 4AP

\begin{tabular}{|c|c|c|c|c|c|c|}
\hline sample & $\begin{array}{l}\text { catalyst } \\
\text { dosage }\end{array}$ & $\begin{array}{l}\text { The } \\
\text { concentration } \\
\text { of } \mathrm{NaBH}_{4}(\mathrm{M})\end{array}$ & $\begin{array}{l}\text { [4-NP] } \\
\text { usage } \\
\text { (mM) }\end{array}$ & $\begin{array}{l}\text { reaction } \\
\text { rate } \\
\text { constant } \\
(\mathrm{k}) \times 10^{-3} \\
\left(\mathrm{~s}^{-1}\right)\end{array}$ & $\begin{array}{l}\text { active factors } \\
\left(\mathrm{k}^{\prime}\right) \times 10^{-3}\left[\mathrm{~s}^{-1} \mathrm{mg}^{-1} \square\right.\end{array}$ & references \\
\hline $\begin{array}{l}\text { 5.1wt\% Co- } \\
\text { doped CuO NPs }\end{array}$ & 1 & 8 & 0.12 & 43.80 & 43.8 & [20] \\
\hline $\mathrm{Cu}_{2} \mathrm{O} \mathrm{NPs}$ & 1 & 0 & 0.1 & 15.7 & 15.7 & [21] \\
\hline $\mathrm{Cu}_{2} \mathrm{O} / \mathrm{MoS}_{2} / \mathrm{rGO}$ & 10 & 6.25 & 12.5 & 62 & 6.2 & [22] \\
\hline $\begin{array}{l}\mathrm{Cu}_{2} \mathrm{O} / \mathrm{Cu}- \\
\mathrm{MOF} / \mathrm{rGO}\end{array}$ & 1 & 100 & 0.1 & 32.7 & 32.7 & [23] \\
\hline $\mathrm{Cu}_{2} \mathrm{O} / \mathrm{ZrO}_{2}$ & 12 & 30 & 0.0625 & 15.97 & 1.331 & [24] \\
\hline $15-\mathrm{cco} / \mathrm{bv}$ & 1 & 50 & 0.1 & 24.8 & 24.8 & [25] \\
\hline $\begin{array}{l}\mathrm{Fe}_{3} \mathrm{O}_{4} @ p p y- \\
\text { MAA/Ag }\end{array}$ & 7.5 & 100 & 40 & 2.383 & 0.3177 & [26] \\
\hline $\mathrm{Pt}-\mathrm{NiO} / \mathrm{G}$ & 1 & 100 & 0.1 & 33.9 & 33.9 & [27] \\
\hline $\begin{array}{l}\text { Ag-Fe bimetallic } \\
\text { NPs }\end{array}$ & 5 & 3.333 & 0.0667 & 1.1 & 0.22 & [28] \\
\hline $\mathrm{Cu}_{2} \mathrm{O} / \mathrm{ZnWO}_{4}-5$ & 0.2 & 0.025 & 0.2 & 25.2 & 126 & This work \\
\hline
\end{tabular}

Fig. 10a The cycle stability test of $\mathrm{ZnWO}_{4} / \mathrm{Cu}_{2} \mathrm{O}-5$ and $\mathbf{b}$ the time required for $\mathrm{ZnWO} 4 / \mathrm{Cu}_{2} \mathrm{O}-5$ to convert the same quality 4-NP

Finally, the stability test was carried out. Due to the small amount of catalyst, in order to avoid the loss caused by recycling, the stability of the catalyst was verified by adding 4-NP repeatedly. The specific operation steps were shown in Section 2.4.2. The relationship between $C_{t} / C_{0}$ and $t$ in the 15 cycles is shown in Fig. 10a. It can be

seen from the figure that after 15 cycles, the degradation effect changed little, still reaching more than $95 \%$. It indicates that catalytic stability was good. The time needed to convert the same mass of 4-NP is shown in Fig. 10b. It can be seen from the figure that the time used increases with the increase of cycles. But it remains unchanged after increasing to a certain extent, which indirectly indicates that it has good cycle stability.

\subsection{Effect of reaction temperature on catalytic hydrogenation of 4-NP}


In order to study the effect of temperature on the activity of the catalyst, the activity tests are carried out at $10^{\circ} \mathrm{C}, 25^{\circ} \mathrm{C}, 40^{\circ} \mathrm{C}, 55^{\circ} \mathrm{C}$ and $70^{\circ} \mathrm{C}$ ( Fig. 11a ), and their k values were obtained by linear fitting of kinetics ( Fig. 11b ). Which are $10.88 \times 10^{-3} \mathrm{~s}^{-1}, 25.20 \times 10^{-3} \mathrm{~s}^{-1}, 24.42 \times 10^{-3} \mathrm{~s}^{-1}, 31.93 \times 10^{-3} \mathrm{~s}^{-1}$ and $31.49 \times 10^{3} \mathrm{~s}^{-1}$, respectively. It can be seen that the variation is large at low temperature, but not obvious at high temperature. It indicates that temperature has some influence on activity of the catalyst. The catalytic effect remained unchanged after the temperature

reached a certain level in the high temperature stage, and $50^{\circ} \mathrm{C}$ was the critical point.

Fig. 11a The relationship between $C_{t} / C_{0}$ and time at different temperatures and

b kinetic fitting graph

\subsection{Valence analysis of catalyst elements before and after reaction}

In order to study the reaction mechanism of 4-NP conversion to 4-AP, the $\mathrm{ZnWO}_{4} / \mathrm{Cu}_{2} \mathrm{O}$ after reaction is characterized by XPS. The full spectrum of $\mathrm{ZnWO}_{4} / \mathrm{Cu}_{2} \mathrm{O}$ shown in Fig. 12a indicates that there is no additional impurity element after the reaction. Fig. $12 b$ and $\mathbf{c}$ shows that peaks of $\mathrm{Zn} 2 \mathrm{p}$ are $1021.7 \mathrm{eV}$ ( $\mathrm{Zn}$ $\left.2 \mathrm{p}_{3 / 2}\right)$ and $1044.8 \mathrm{eV}\left(\mathrm{Zn} 2 \mathrm{p}_{1 / 2}\right)$, and the peaks of $\mathrm{W} 4 \mathrm{f}$ are $35.3 \mathrm{eV}\left(\mathrm{W}_{4 / 2}\right)$ and $37.5 \mathrm{eV}\left(\mathrm{W}_{4 f_{5 / 2}}\right)$. Compared with Fig. $6 a$ and $\mathbf{b}$, the spectral peaks of W4f move slightly. But there is one more peak in $01 \mathrm{~s}$ and $\mathrm{Cu} 2 \mathrm{p}$, and the peak is $532.4 \mathrm{eV}$, indicating the formation of CuO. The peaks at $934.7 \mathrm{eV}, 954.6 \mathrm{eV}$ and $943.3 \mathrm{eV}, 962.5 \mathrm{eV}$ also indicate the formation of $\mathrm{CuO}$ in Fig. 12e. The peaks at $932.4 \mathrm{eV}$ and $952.2 \mathrm{eV}$ are $\mathrm{Cu}^{+} / \mathrm{Cu}$. Since it is difficult to distinguish the two by XPS, the valence state of copper ions can only be determined by X-ray induced Auger electron spectroscopy (XAES). The obtained figure shows three independent peaks. The main peak at about $570 \mathrm{eV}$ is considered to represent $\mathrm{Cu}^{+}$, while the peak at about $567 \mathrm{eV}$ is considered to represent $\mathrm{CuO}[17,18]$. The ratio of peak area of $\mathrm{Cu}_{2} \mathrm{O}$ to $\mathrm{Cu}$ in the catalyst decreased from 3.57 to 2.43 before and after the reaction, and the presence of $\mathrm{CuO}$ indicated the formation of $\mathrm{Cu}$. Sasmal et al. [19] reported that $\mathrm{Cu}_{2} \mathrm{O}$ was easily reduced to $\mathrm{Cu}$ by $\mathrm{NaBH}_{4}$ at pH about 9, while $\mathrm{Cu}$ was easily oxidized to $\mathrm{CuO}$, and finally formed ternary complexes. The presence of $\mathrm{Cu}$ is very important for the reduction of 4-NP, which can absorb hydrogen and is the action site of $\mathrm{BH}_{4}{ }^{-}$. The shift of the binding energy peaks of $\mathrm{Zn} 2 \mathrm{p}$ and $\mathrm{W} 4 \mathrm{f}$ and the generation and shift of the binding energy peaks of $\mathrm{O} 1 \mathrm{~s}$ and $\mathrm{Cu} 2 \mathrm{p}$ indicate that they interact.

Fig. 12a The XPS survey spectrum of the recycled $\mathrm{ZnWO}_{4} / \mathrm{Cu}_{2} \mathrm{O}$; the high-resolution XPS spectra for $\mathbf{b} \mathrm{Zn}$ $2 p, \mathbf{c W} 4 \mathrm{f}, \mathbf{d} \mathrm{O} 1 \mathrm{~s}, \mathbf{e} \mathrm{Cu} 2 \mathrm{p}, \mathbf{f} \mathrm{Cu} L \mathrm{LMM}$ of the refreshed and $\mathbf{g}$ the used Cu LMM

\subsection{Electrochemical impedance performance test}

In order to study the charge transfer process and the separation efficiency of charge carriers, electrochemical impedance spectroscopy (EIS) was performed on $\mathrm{Cu}_{2} \mathrm{O}, \mathrm{ZnWO}_{4}$ and $\mathrm{ZnWO}_{4} / \mathrm{Cu}_{2} \mathrm{O}$. In general, the Nyquist radius is related to the charge transfer efficiency. And the charge transfer impedance with smaller radius is low. As shown in Fig. 13, the arc size of the prepared samples is observed to be 
$\mathrm{ZnWO}_{4} / \mathrm{Cu}_{2} \mathrm{O}<\mathrm{Cu}_{2} \mathrm{O}<\mathrm{ZnWO}_{4}$. The interaction between $\mathrm{Cu}_{2} \mathrm{O}$ and $\mathrm{ZnWO}_{4}$ improved the electron transfer effect of $\mathrm{ZnWO}_{4} / \mathrm{Cu}_{2} \mathrm{O}$ composites.

Fig. 13 Electrochemical impedance (EIS) curves of $\mathrm{Cu}_{2} \mathrm{O}, \mathrm{ZnWO}_{4}$ and $\mathrm{ZnWO}_{4} / \mathrm{Cu}_{2} \mathrm{O}$

\section{Conclusions}

In short, a new degradation process of 4-NP by new composite $\mathrm{ZnWO}_{4} / \mathrm{Cu}_{2} \mathrm{O}$ was reported. As shown in Fig. 14. The special structure of $\mathrm{ZnWO}_{4}$ improves the narrow band gap of $\mathrm{Cu}_{2} \mathrm{O}$. The electron-hole separation ability and photocatalytic activity of the composite are enhanced. In addition, during the catalytic process, $\mathrm{ZnWO}_{4}$ quickly transferred electrons to 4-NP ions on the catalyst surface. Generate an electrically neutral 4-AP and desorb it. The active sites were transferred and the reaction could continue. The results show that the cycle utilization and stability are enhanced.

\section{Declarations}

\section{Acknowledgements}

This work was financially supported by Sichuan Province Science and Technology Support Program (2021YJ0323).

\section{Author information}

Affiliations

College of Chemical and Biological Engineering, China West Normal University, Sichuan, 637002, China (all people)

Ziwei Wang ${ }^{+1}$ (E-mail:2021098527@qq.com), Fengping Fu+(E-mail:1205160551

@qq.com), Qian He(E-mail: 2437675878@qq.com), Ting Zhu(E-mail:1627765581

@qq.com), Fang Liao*(E-mail:liaofang407@163.com)

+1 : This is senior author ; +: These authors contributed equally; *: Corresponding author

\section{Corresponding authors}

Correspondence to Fang Liao (E-mail:liaofang407@163.com ).

\section{Statements and Declarations}

Compliance with Ethical Standards

\section{Conflict of interest}


There are no conflict of interest.

Research not involving Human Participants and Animals.

known and agreed.

\section{Bankroll}

This work was financially supported by Sichuan Province Science and Technology Support Program (2021YJ0323).

\section{References}

1. Bhatt D, Gururani N, Srivastava A, et al. Sorption studies of 4-NP onto goethite: effects of contact time, $\mathrm{pH}$, concentration, ionic strength and temperature[J]. Environmental Earth Sciences, 2021, 80(7): 273.

2. Zhang X-F, Zhu X-Y, Feng J-J, et al. Solvothermal synthesis of N-doped graphene supported PtCo nanodendrites with highly catalytic activity for 4-nitrophenol reduction[J]. Applied Surface Science, 2018, 428: 798-808.

3. Ghosh B K, Hazra S, Naik B, et al. Preparation of Cu nanoparticle loaded SBA-15 and their excellent catalytic activity in reduction of variety of dyes[J]. Powder Technology, 2015, 269: 371-378.

4. Maryam B, Nafiseh M. Biosynthesis of waste pistachio shell supported silver nanoparticles for the catalytic reduction processes[J]. IET Nanobiotechnology, 2018, 12(7): 939-945.

5. Suchintak D, Sourav D, Md Imran K, et al. Sonochemically synthesized $\mathrm{Ag} / \mathrm{CaCO}_{3}$ nanocomposites: A highly efficient reusable catalyst for reduction of 4-nitrophenol[J]. Materials Chemistry and Physics, 2018, 220: 409-416.

6. LUO J S, LUD \&ILLA S, MIN-KYU S, et al. $\mathrm{Cu}_{2} \mathrm{O}$ nanowire photocathodes for efficient and durable solar water splitting [J]. Nano Letters, 2016, 16(3): 1848-1857.

7. MORALES-GUIO C G, LIARDET L, MAYER M T, et al. Photoelectrochemical hydrogen production in alkaline solutions nsing $\mathrm{Cu}_{2} \mathrm{O}$ coated with earth-abundant hydrogen eVolution catalysts[J]. Angewandte Chemie(International Edition), 2015, 54(2): 664-667.

8. Xu C, Chunxin $\mathrm{Y}$, Xiaojiao G, et al. $\mathrm{Cu}_{2} \mathrm{O}$ Nanoparticles and Multi-Branched Nanowires as Anodes for Lithium-Ion Batteries[J]. Nano, 2018, 13(9): 1850103.

9. Sourav G, Rituparna D, Milan Kanti N. Understanding of water-assisted template-free synthesis of $\mathrm{Cu}_{2} \mathrm{O}$ microrods[J]. Materials Letters, 2017, 213: 262-265.

10. Sourav R, Matteo B, Alberto N, et al. Well-defined $\mathrm{Cu}_{2} \mathrm{O}$ photocatalysts for solar fuels and chemicals[J]. Journal of Materials Chemistry A, 2021, 9: 5915-5951.

11. Hongmei $W$, Zhufeng $L$, Dingze $L$, et al. A surfactant-free solvothermal synthesis of $\mathrm{Cu}_{2} \mathrm{O}$ microcrystals and their photocatalytic activity[J]. Water Science and Technology, 2016, 73(10): 2379-2385.

12. Gang W, Roy Van Den B, Celso De Mello D, et al. Silica-supported $\mathrm{Cu}_{2} \mathrm{O}$ nanoparticles with tunable size for sustainable hydrogen generation[J]. Applied Catalysis B: Environmental, 2016, 192: 199-207. 
13. Yanan G, Long Z, Arno J F V H, et al. On the surface-dependent oxidation of $\mathrm{Cu}_{2} \mathrm{O}$ during $\mathrm{CO}$ oxidation: $\mathrm{Cu}^{2+}$ is more active than $\mathrm{Cu}^{+}[\mathrm{J}]$. Applied Catalysis A: General, 2020, 602:117712.

14. Maryam B, Neda N, Mahmoud N. Melissa Officinalis L. leaf extract assisted green synthesis of $\mathrm{CuO} / \mathrm{ZnO}$ nanocomposite for the reduction of 4-nitrophenol and Rhodamine B[J]. Separation and Purification Technology, 2017, 191: 295-300.

15. Akbarzadeh E, Rahman Setayesh S, Gholami M R. Investigating the role of $\mathrm{MoS}_{2}$ /reduced graphene oxide as cocatalyst on $\mathrm{Cu}_{2} \mathrm{O}$ activity in catalytic and photocatalytic reactions[J]. New Journal of Chemistry, 2017, 41(16): 7998-8005.

16. Tian L, Rui Y, Sun K, et al. Surface Decoration of $\mathrm{ZnWO}_{4}$ Nanorods with $\mathrm{Cu}_{2} \mathrm{O}$ Nanoparticles to Build Heterostructure with Enhanced Photocatalysis[J]. Nanomaterials (Basel), 2018, 8(1): 33.

17. Coşkuner Filiz B. The role of catalyst support on activity of copper oxide nanoparticles for reduction of 4-nitrophenol[J]. Advanced Powder Technology, 2020, 31(9): 3845-3859.

18. Mirzaee Valadi F, Gholami M R. Synthesis of $\mathrm{CuCO}_{2} \mathrm{O}_{4} / \mathrm{BiVO}_{4}$ composites as promise and efficient catalysts for 4-nitrophenol reduction in water: Experimental and theoretical study[J]. Journal of Environmental Chemical Engineering, 2021, 9(4): 105408.

19. Chang J, Bao Q, Zhang C, et al. Rapid preparation and photocatalytic properties of octahedral $\mathrm{Cu}_{2} \mathrm{O} @ \mathrm{Cu}$ powders[J]. Advanced Powder Technology, 2021, 32(1): 144-150.

20. Sharma A, Dutta R K, Roychowdhury A, et al. Cobalt doped CuO nanoparticles as a highly efficient heterogeneous catalyst for reduction of 4-nitrophenol to 4-aminophenol[J]. Applied Catalysis A: General, 2017, 543: 257-265.

21. Sasmal A K, Dutta S, Pal T. A ternary $\mathrm{Cu}_{2} \mathrm{O}-\mathrm{Cu}-\mathrm{CuO}$ nanocomposite: a catalyst with intriguing activity[J]. Dalton Trans, 2016, 45(7): 3139-50.

22. Akbarzadeh E, Rahman Setayesh S, Gholami M R. Investigating the role of $\mathrm{MoS}_{2}$ /reduced graphene oxide as cocatalyst on $\mathrm{Cu}_{2} \mathrm{O}$ activity in catalytic and photocatalytic reactions[J]. New Journal of Chemistry, 2017, 41(16): 7998-8005.

23. Akbarzadeh E, Soheili $\mathrm{HZ}$, Gholami M R. Novel $\mathrm{Cu}_{2} \mathrm{O} / \mathrm{Cu}-\mathrm{MOF} / \mathrm{rGO}$ is reported as highly efficient catalyst for reduction of 4-nitrophenol[J]. Materials Chemistry and Physics, 2019, 237: 121846.

24. Coşkuner Filiz B. The role of catalyst support on activity of copper oxide nanoparticles for reduction of 4-nitrophenol[J]. Advanced Powder Technology, 2020, 31(9): 3845-3859.

25. Mirzaee Valadi F, Gholami M R. Synthesis of $\mathrm{CuCO}_{2} \mathrm{O}_{4} / \mathrm{BiVO}_{4}$ composites as promise and efficient catalysts for 4-nitrophenol reduction in water: Experimental and theoretical study[J]. Journal of Environmental Chemical Engineering, 2021, 9(4): 105408.

26. Das R, Sypu V S, Paumo H K, et al. Silver decorated magnetic nanocomposite $\left(\mathrm{Fe}_{3} \mathrm{O}_{4} @ P P y-M A A / A g\right)$ as highly active catalyst towards reduction of 4-nitrophenol and toxic organic dyes[J]. Applied Catalysis B: Environmental, 2019, 244: 546-558.

27. Akbarzadeh $\mathrm{E}$, Gholami M R. Pt-NiO- $\mathrm{Al}_{2} \mathrm{O}_{3} / \mathrm{G}$ derived from graphene-supported layered double hydroxide as efficient catalyst for 4-nitrophenol reduction[J]. Research on Chemical Intermediates, 
2017, 43(10): 5829-5839.

28. Malik M A, Alshehri A A, Patel R. Facile one-pot green synthesis of Ag-Fe bimetallic nanoparticles and their catalytic capability for 4-nitrophenol reduction[J]. Journal of Materials Research and Technology, 2021, 12: 455-470.

29. Chang J, Bao Q, Zhang C, et al. Rapid preparation and photocatalytic properties of octahedral $\mathrm{Cu}_{2} \mathrm{O} @ \mathrm{Cu}$ powders[J]. Advanced Powder Technology, 2021, 32(1): 144-150.

30. Chang J, Bao Q, Zhang C, et al. Rapid preparation and photocatalytic properties of octahedral $\mathrm{Cu}_{2} \mathrm{O} @ \mathrm{Cu}$ powders[J]. Advanced Powder Technology, 2021, 32(1): 144-150.

31. Hu Y, Yang S, Tao B, et al. Catalytic decomposition of ammonium perchlorate on hollow mesoporous CuO microspheres[J]. Vacuum, 2019, 159: 105-111.

\section{Figures}

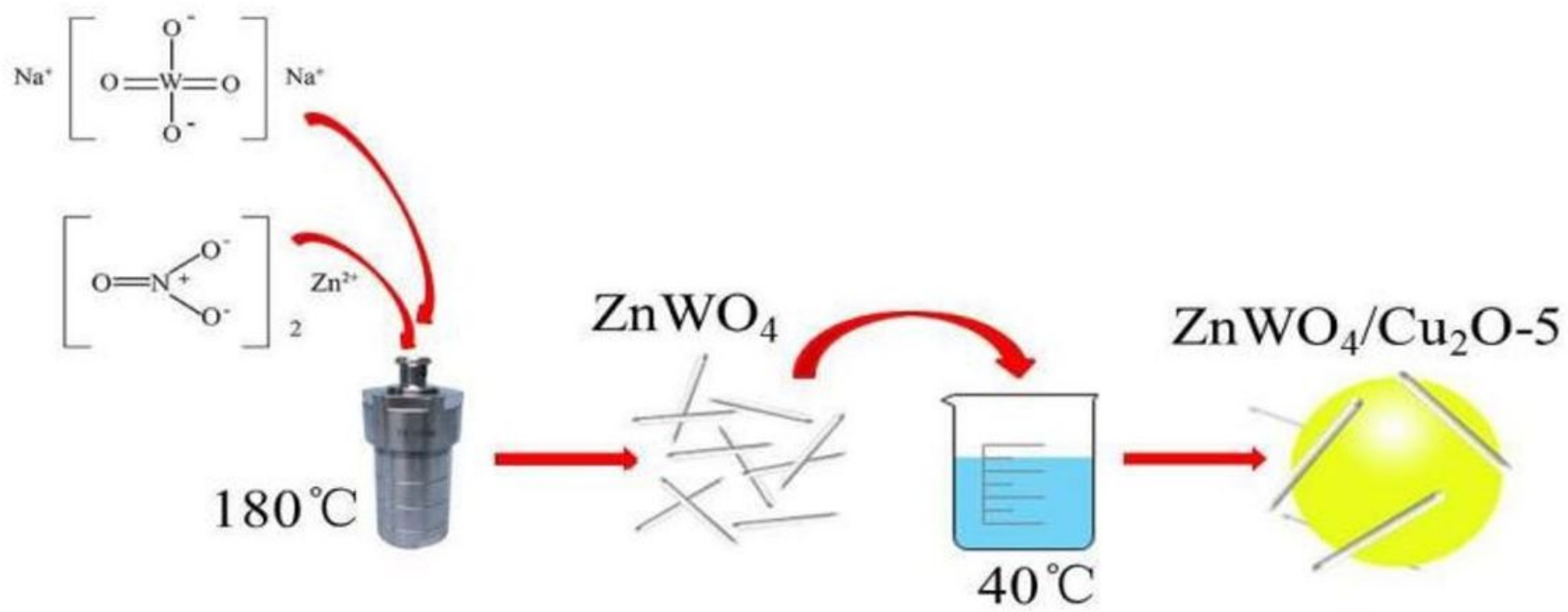

\section{Figure 1}

Preparation process of ZnW04/Cu2O composite 


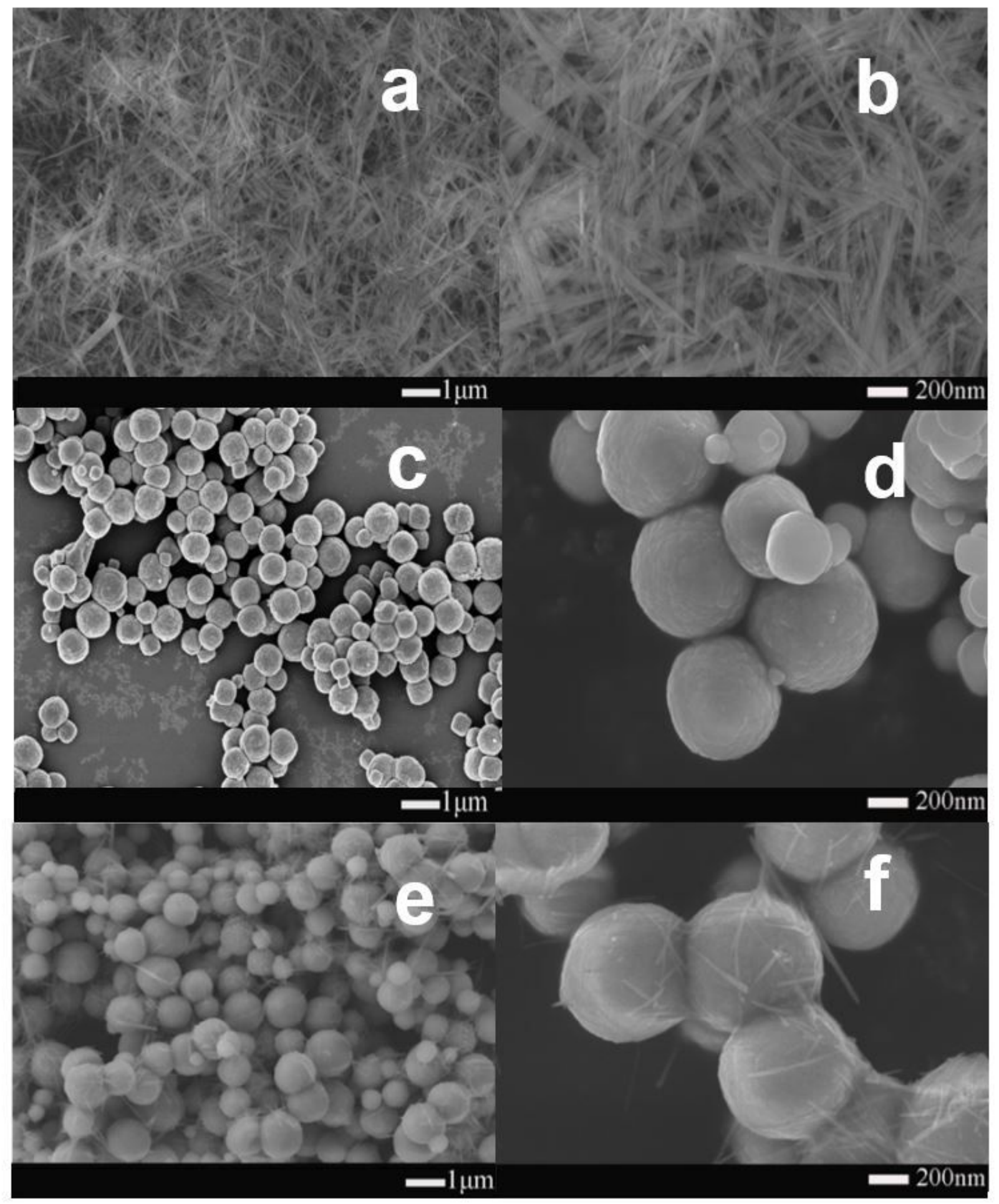

Figure 2

SEM images of (a-b) ZnWO4; (c-d) Cu2O; (e-f) ZnWO4/Cu2O 

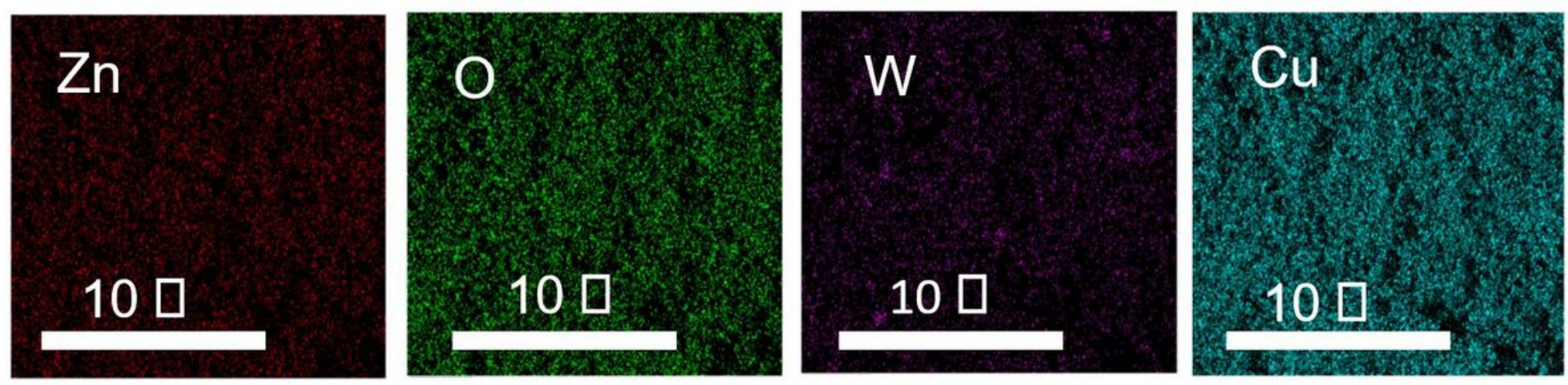

Figure 3

Mapping images of ZnWO4/Cu2O (Disrribution of Zn, O, W and Cu)
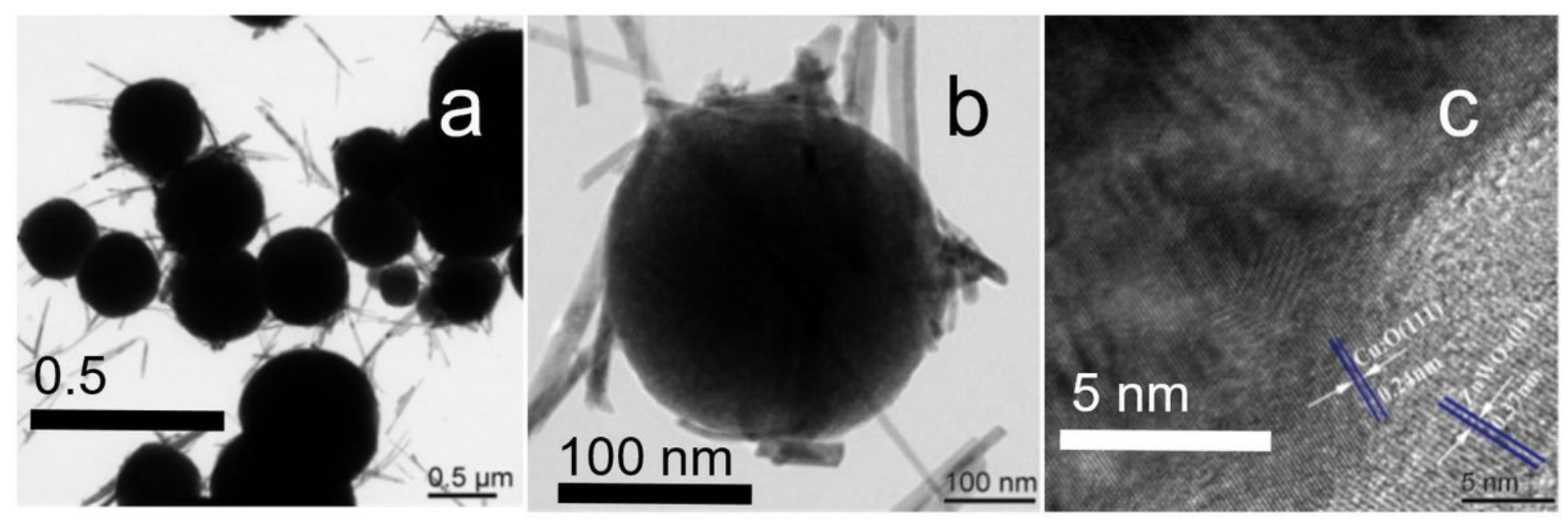

Figure 4

TEM and HRTEM images of ZnWO4/Cu2O 


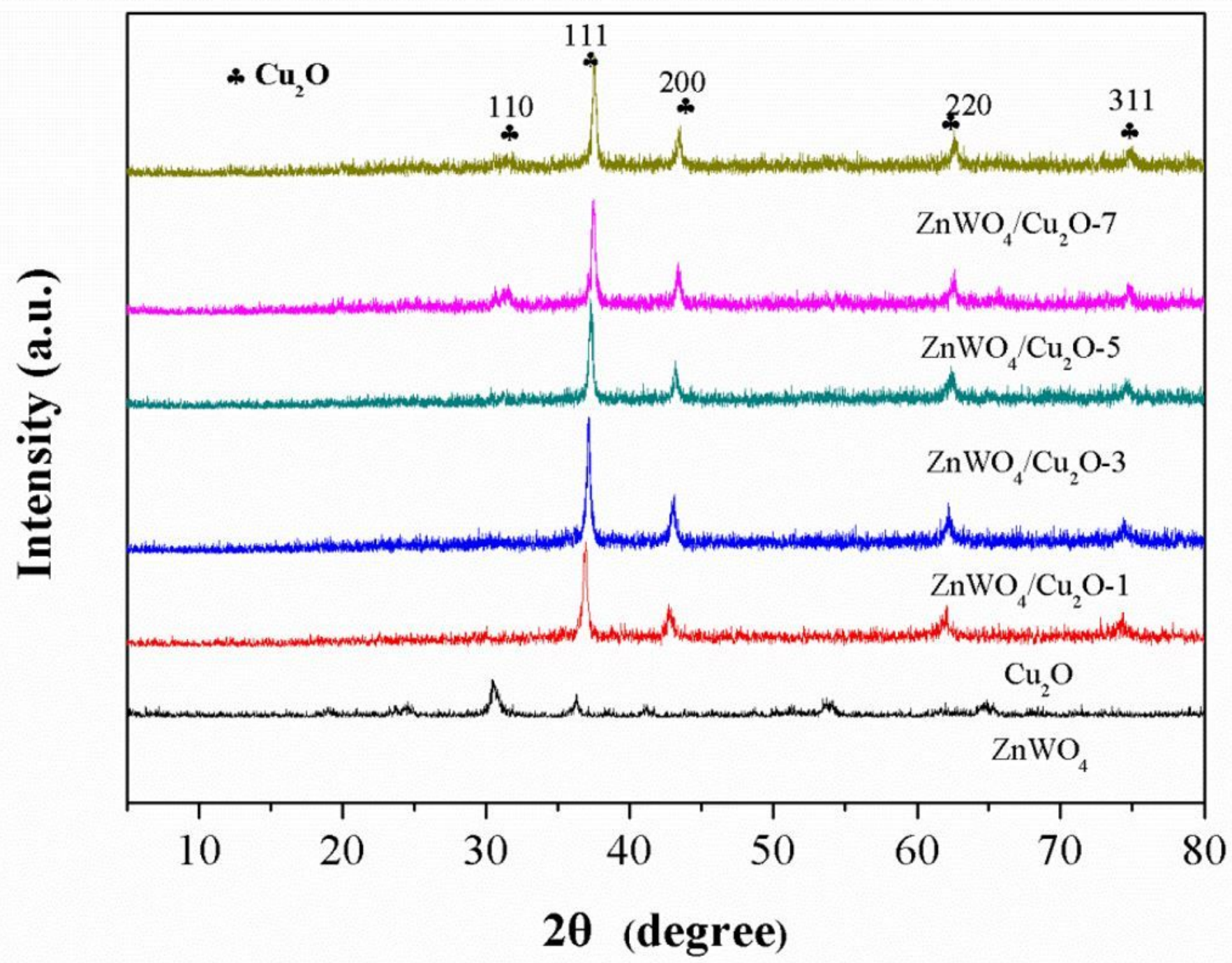

Figure 5

XRD patterns of ZnWO4; Cu2O; ZnWO4/Cu2O-X 

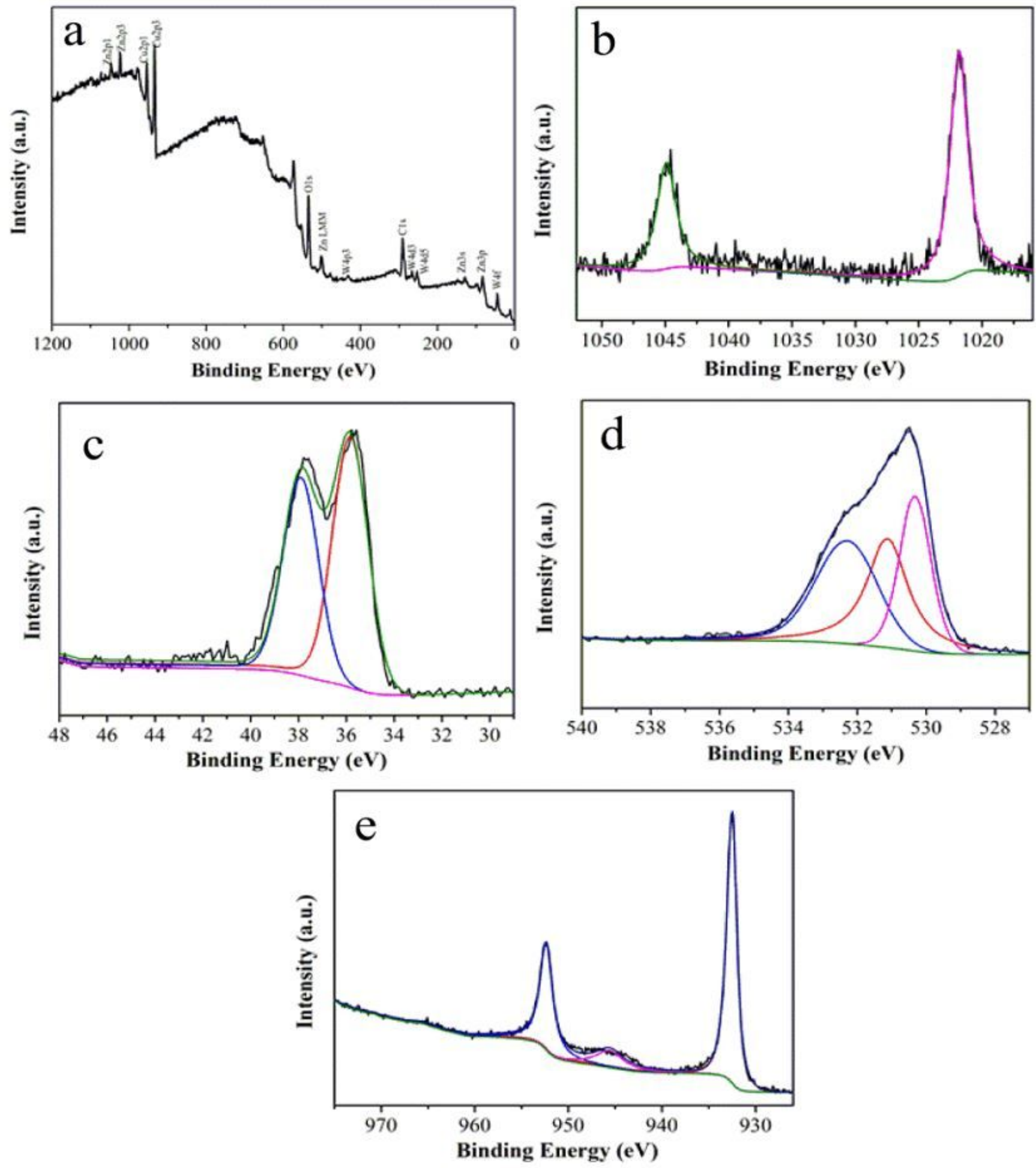

Figure 6

a XPS survey spectra; High-resolution XPS spectra of b Zn 2p; c W 4f; d O 1s and e Cu 2p 

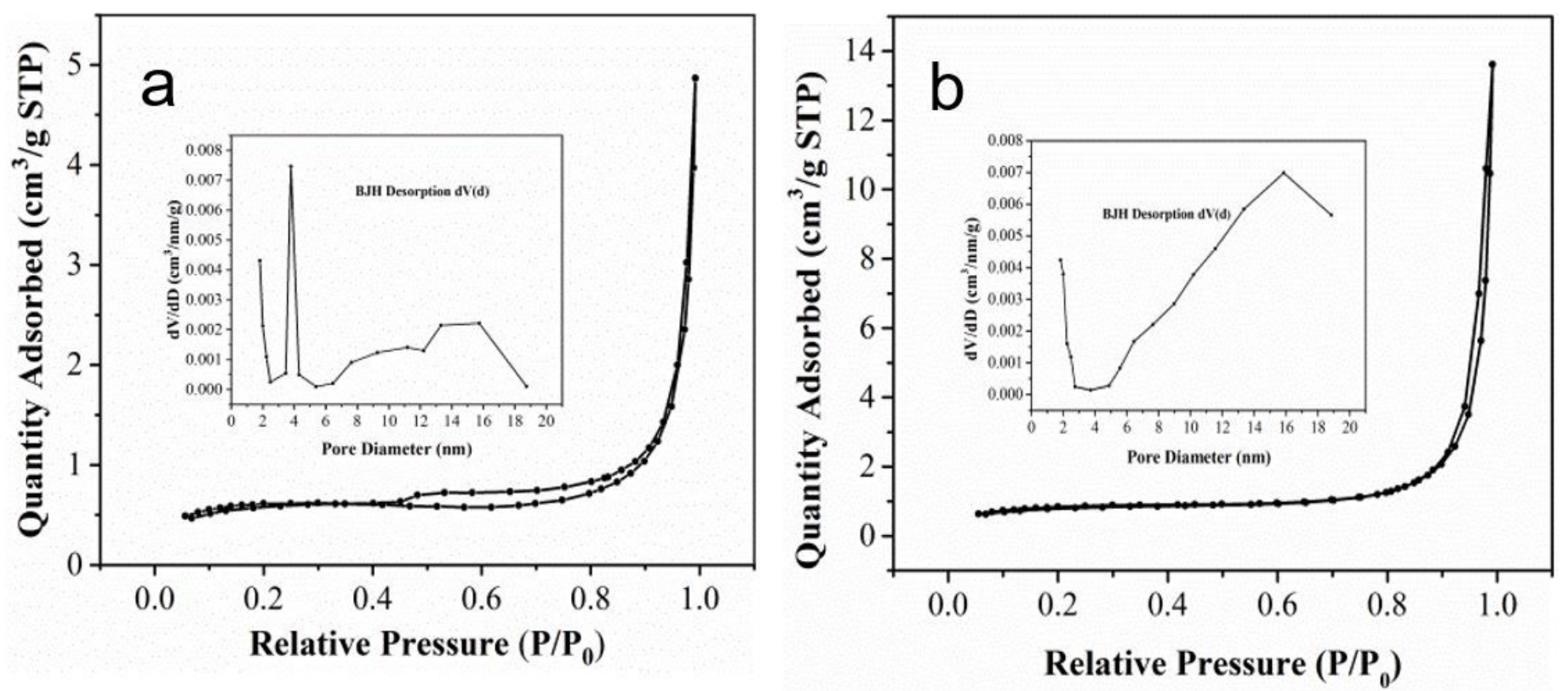

Figure 7

N2 adsorption and desorption curves of a Cu2O; b ZnWO4/Cu2O
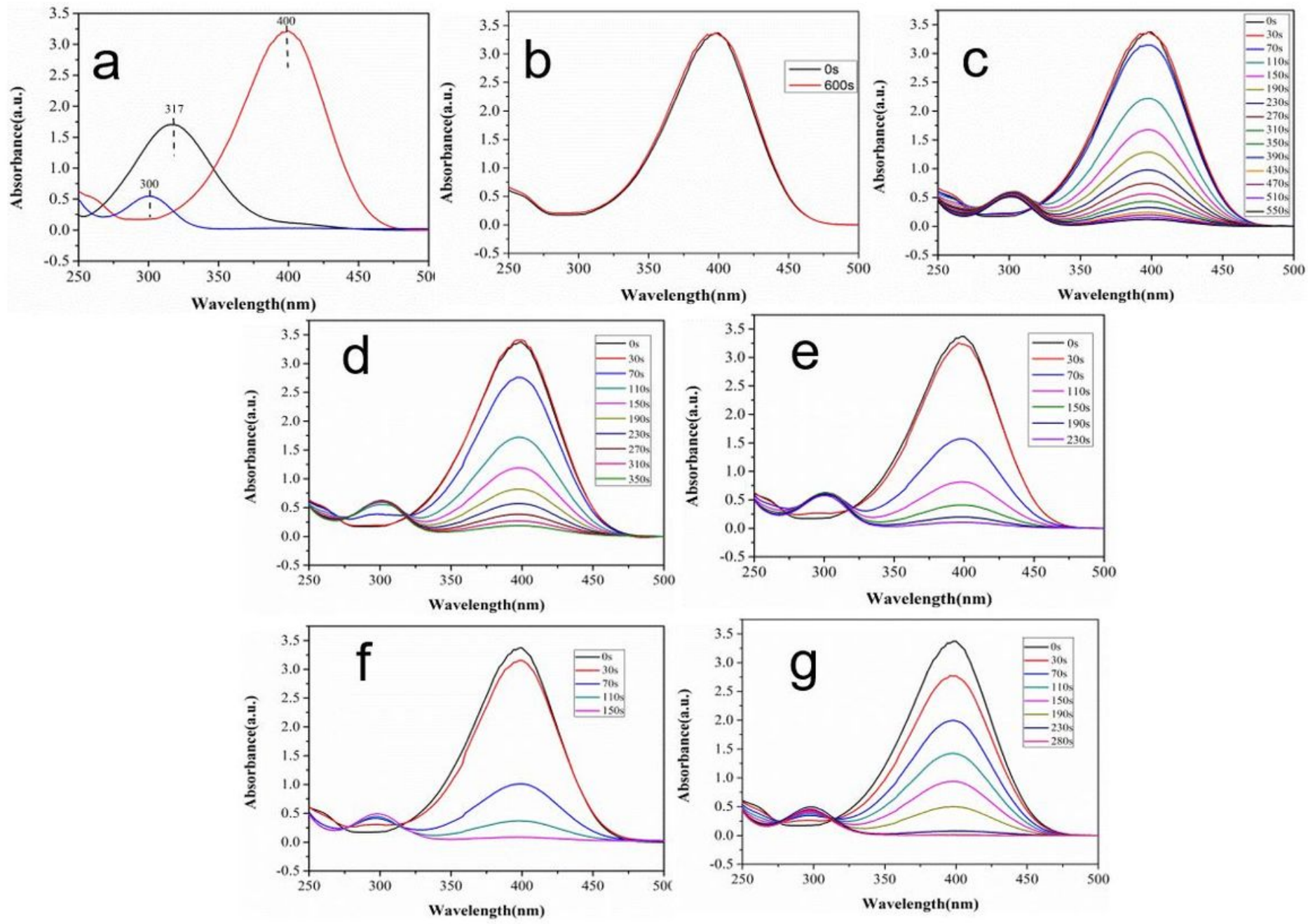
Figure 8

a UV-Vis absorption spectra of the 4-NP reaction process catalyzed by hydrogenation; UV-Vis absorption spectra of b ZnW04, c Cu2O, d ZnWO4/Cu2O-1, e ZnW04/Cu2O-3, f ZnWO4/Cu2O-5, g ZnWO4/Cu2O-7 catalytic reduction of 4-NP
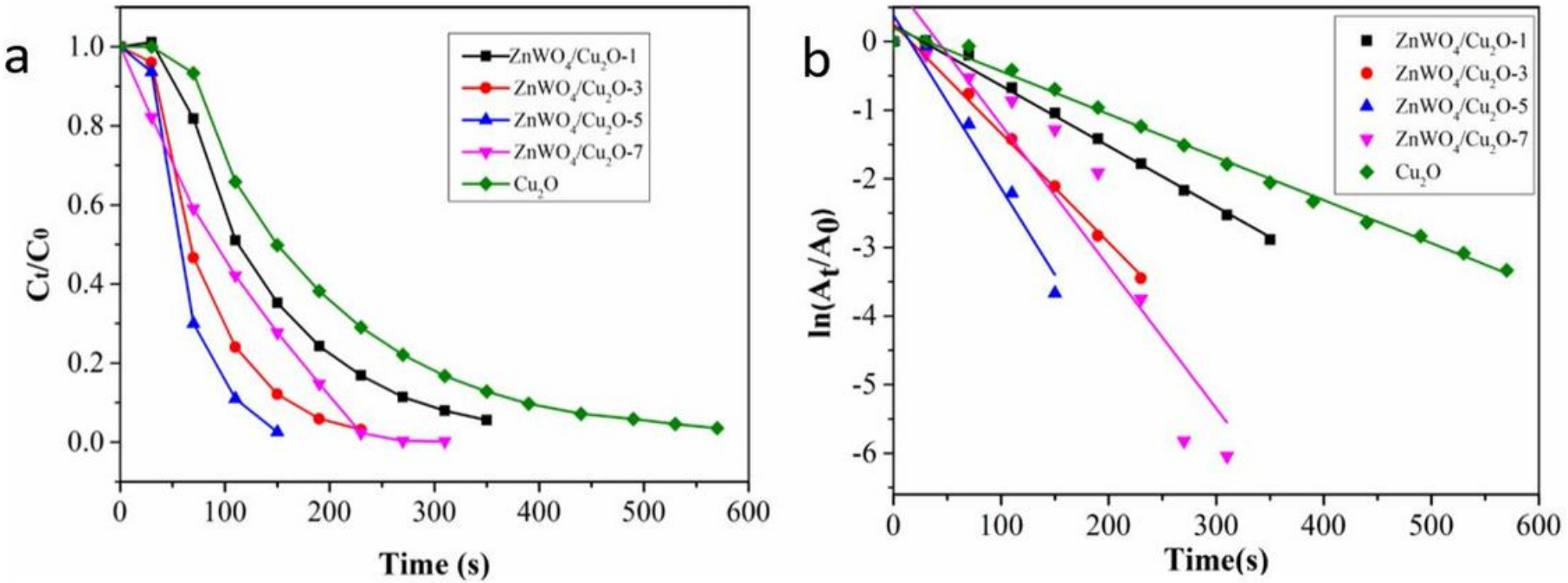

Figure 9

Different catalysts of a Ct / CO curve graph with time; b netic fitting graph
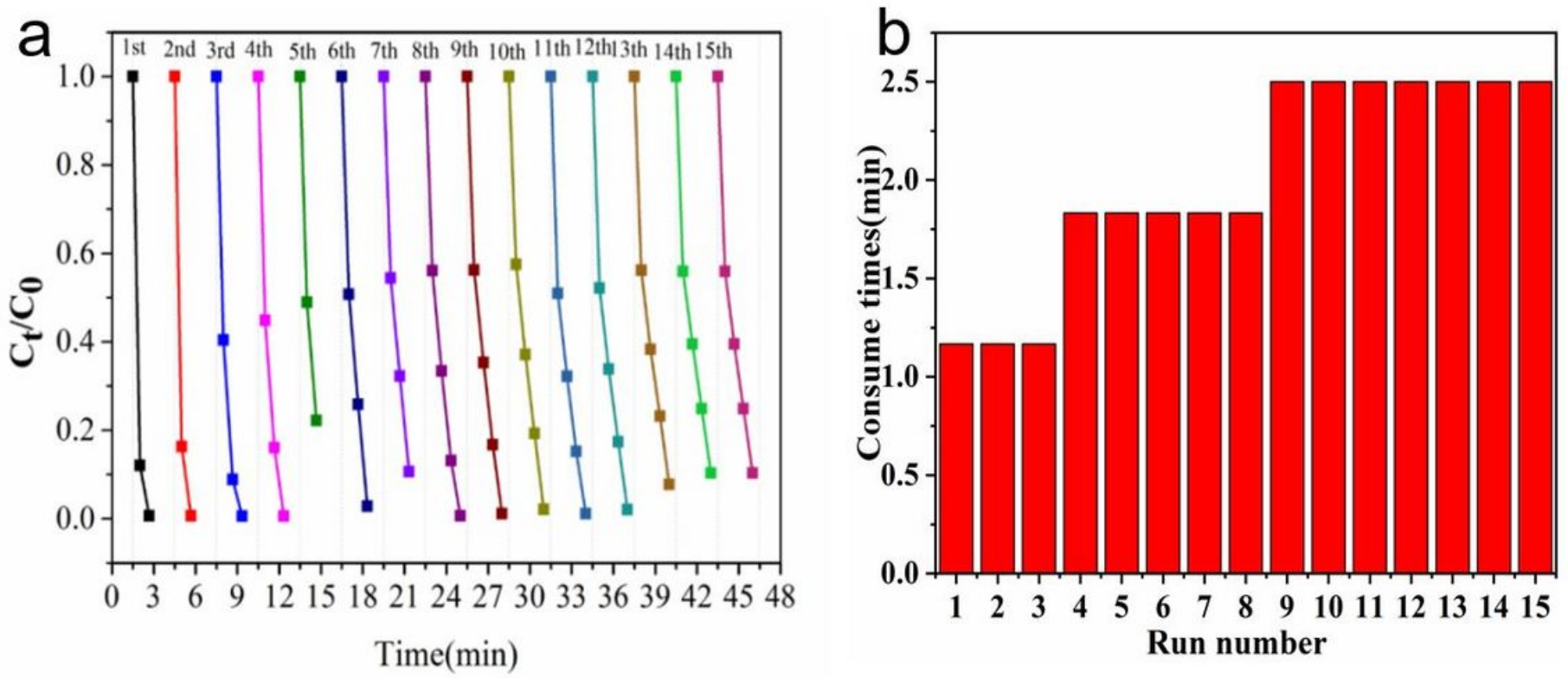

Figure 10

a The cycle stability test of ZnWO4/Cu2O-5 and b the time required for ZnWO4/Cu2O-5 to convert the same quality 4-NP 

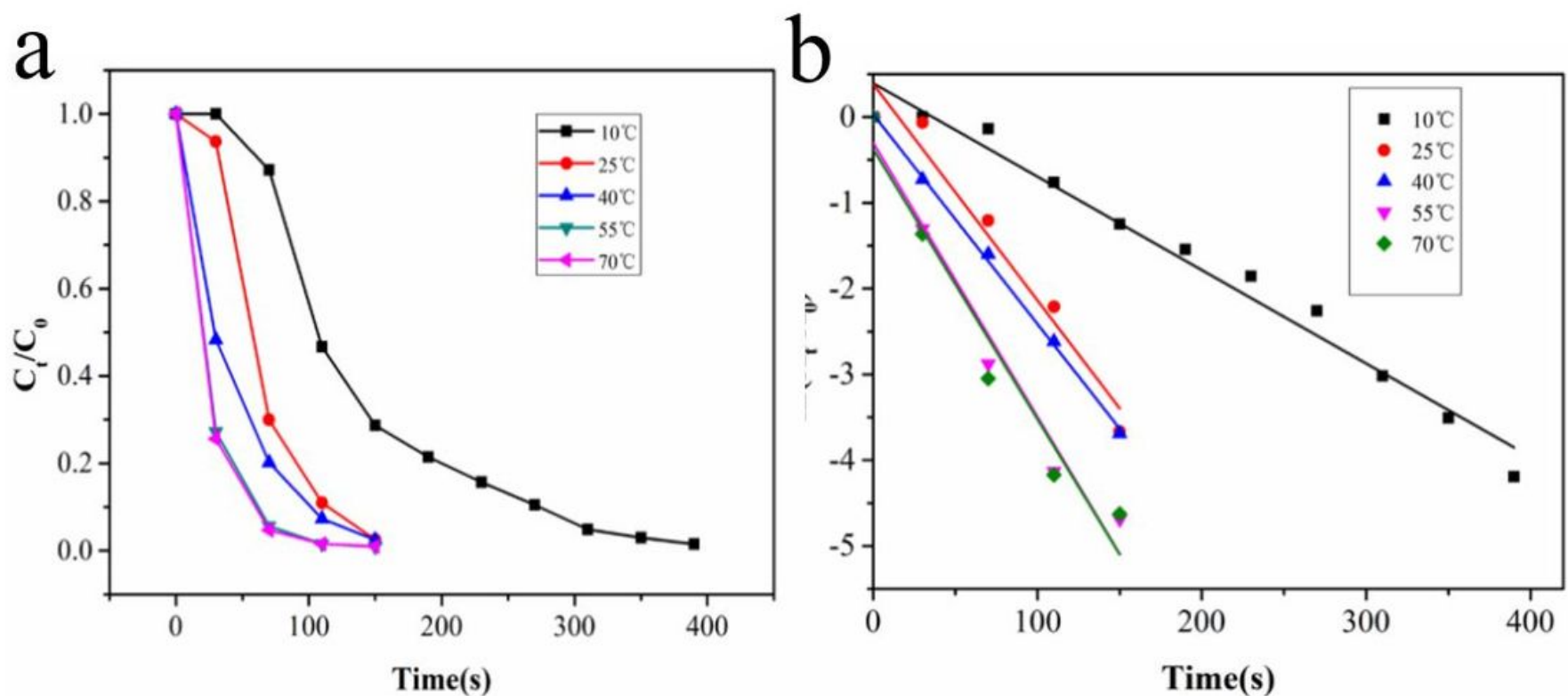

Figure 11

a The relationship between $\mathrm{Ct} / \mathrm{CO}$ and time at different temperatures and $\mathrm{b}$ kinetic fitting graph 

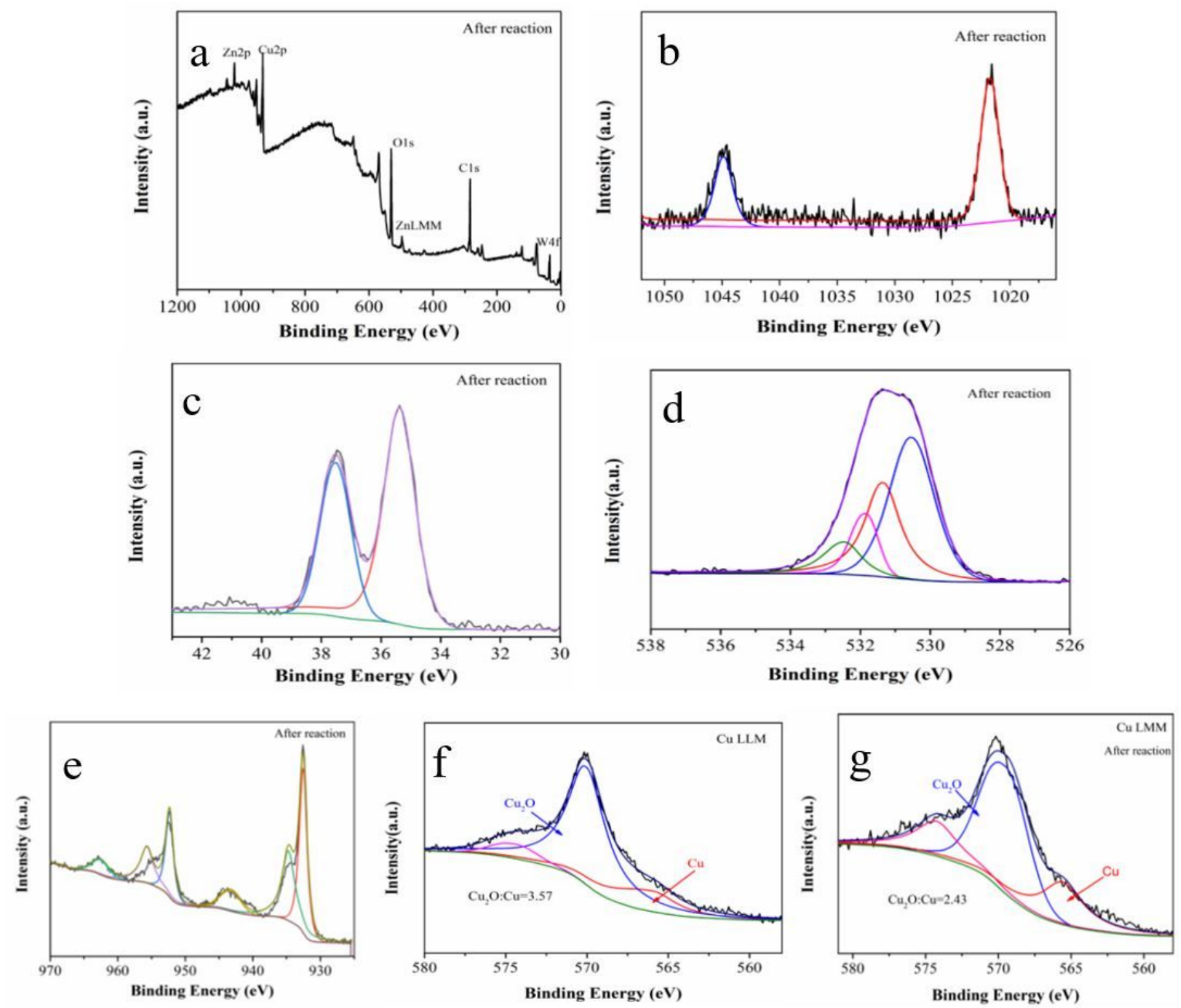

Figure 12

a The XPS survey spectrum of the recycled ZnWO4/Cu2O; the high-resolution XPS spectra for b Zn 2p, c W $4 f, d ~ O 1 s, e ~ C u ~ 2 p, f$ Cu LMM of the refreshed and g the used Cu LMM 


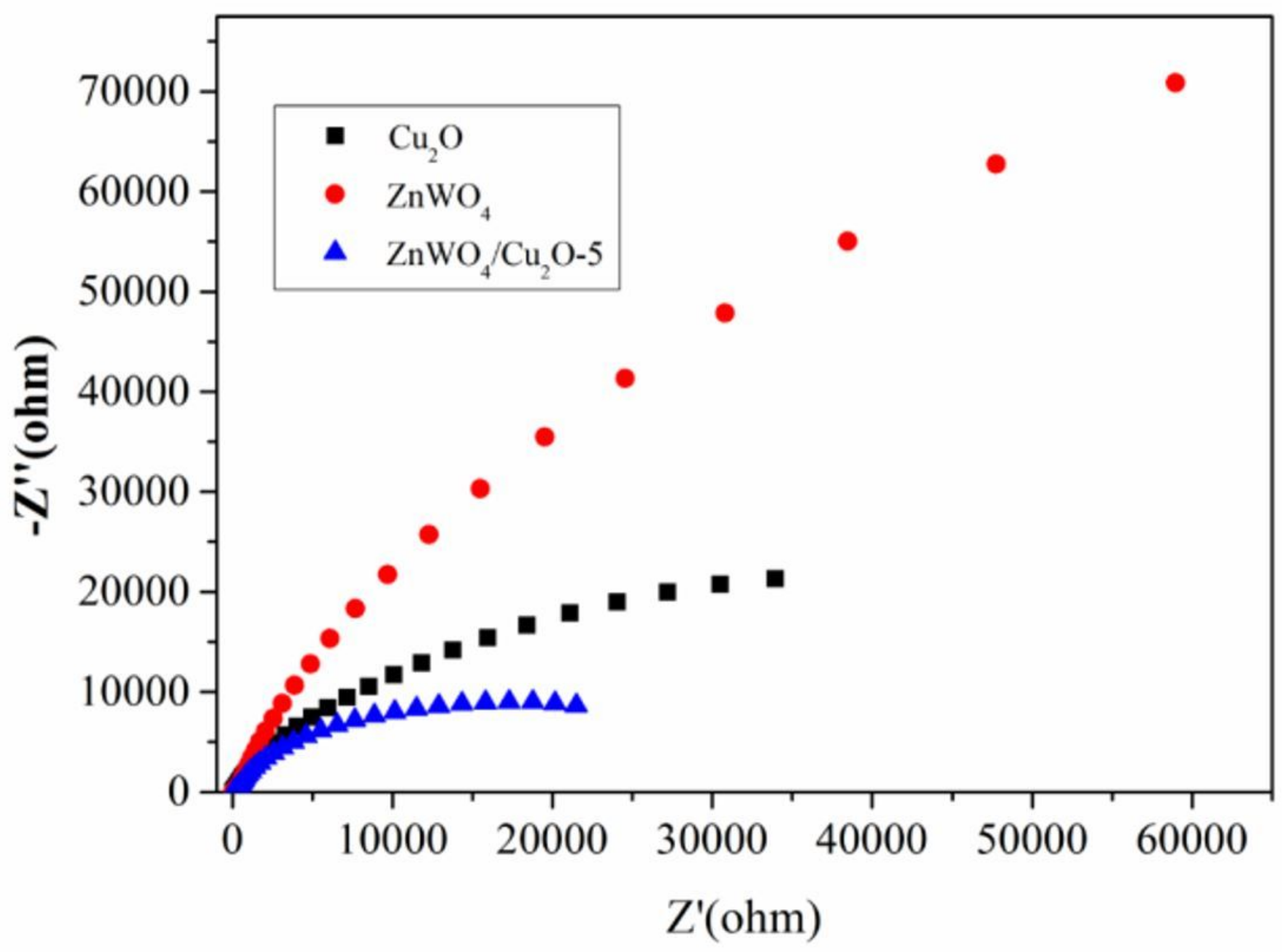

Figure 13

Electrochemical impedance (EIS) curves of Cu2O, ZnWO4 and ZnWO4/Cu2O 


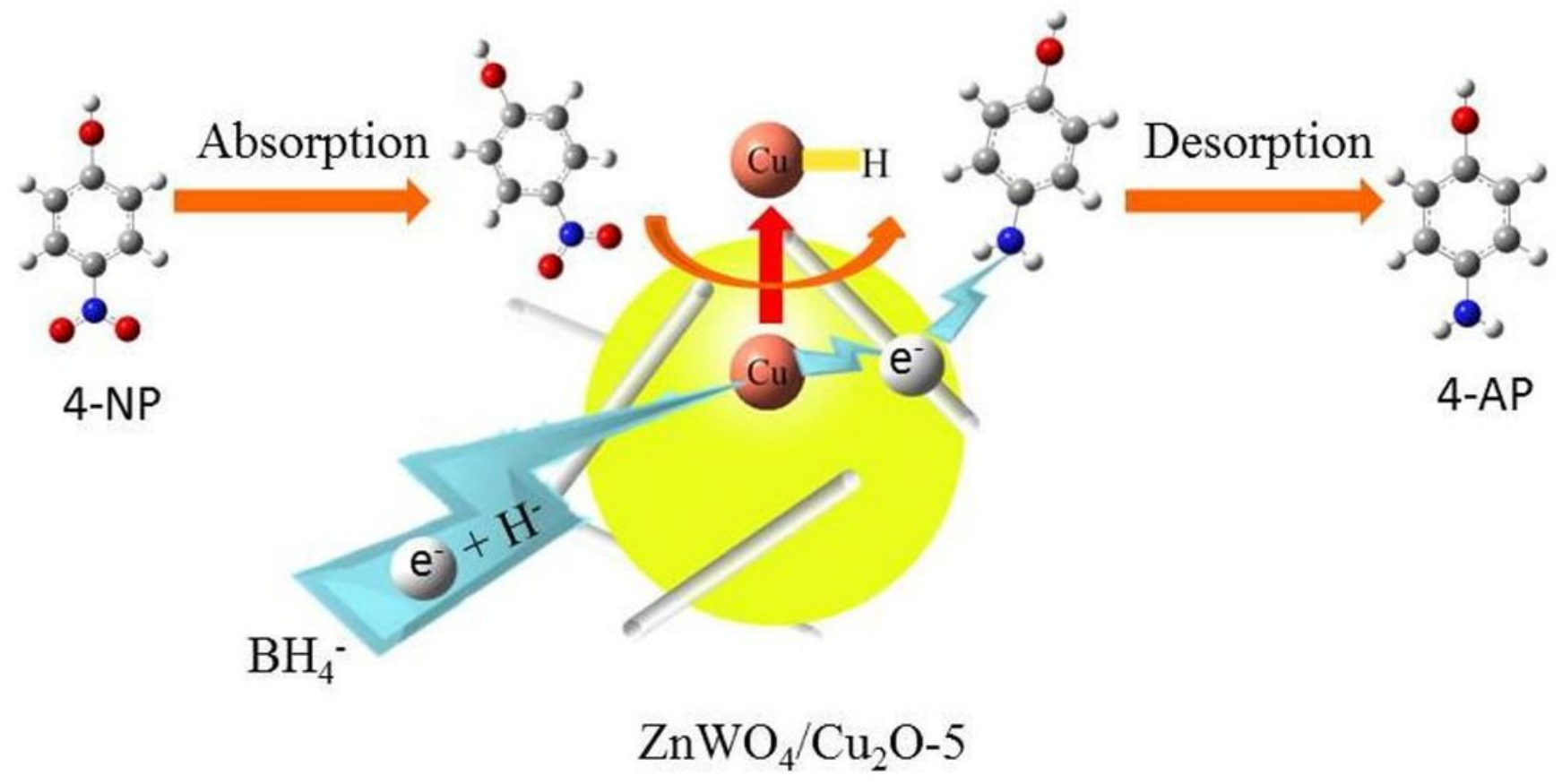

Figure 14

Diagram of the catalytic reaction mechanism of $\mathrm{ZnWO4/Cu2O}$ 